$\begin{gathered}\text { EPiC Series in Education Science } \\ \text { Volume 1, 2017, Pages 371-378 }\end{gathered}$
$\begin{gathered}\text { AUBEA 2017: Australasian Universities Build- } \\ \text { ing Education Association Conference 2017 }\end{gathered}$
$\begin{gathered}\text { Education } \\ \text { Science }\end{gathered}$

\title{
Tall Building Design Exploration: Designing For Wind Resilience
}

\author{
Mohamed Khallaf ${ }^{1}$ and Julie Jupp ${ }^{2}$ \\ ${ }^{1,2}$ University of Technology Sydney, Australia. \\ mohamed.khallaf@uts.edu.au, julie.jupp@uts.edu.au
}

\begin{abstract}
The paper presents a performance-based design method that combines building and urban objectives for the control of winds impacting on tall buildings at the pedestrian, podium and upper levels. The performance-based method accounts for wind flow and wind load in a design exploration technique that considers a variety of criteria defining urban microclimates, defined by high-density, multi-level building forms subject to acute variations in seasonal wind conditions. The approach is based on the theoretical foundations of 'designing for urban resilience; and highlights the different objectives of this approach relative to existing (tall) building design standards and urban city planning guidelines.
\end{abstract}

\section{Introduction}

In the development and promotion of sustainable urban planning strategy and building design practices, the concept of resilience has become a central aspect of modern cities. By 2050, the United Nations expects 80 percent of the world's population to live in urban areas (United Nations 2009). In addition, over 310 million people live in cities with a high probability of natural disasters including the effects of hurricanes and tropical cyclones, and by 2050 these numbers are predicted to more than double (Lall \& Deichmann 2012). As cities continue to expand and grapple with the uncertainties and challenges of climate change and unprecedented urbanization there is a growing emphasis on enhancing the resilience of cities (Meerow 2016)

In the implementation of tall building design standards and urban city development design guidelines, separate policies aimed at the building and urban scale stipulate how a variety of safety, health and comfort requirements must be supported. Recent initiatives surrounding 'designing for urban resilience' have adopted a more integrated 'systems' approach to building design aimed at supporting the survival, adaptation, and growth of cities against chronic environmental stresses and acute shocks. Mitigating the impacts of strong or extreme winds at the building and urban city scale is key to urban resilience. 
This paper reviews literature surrounding 'designing for urban resilience' and highlights the different objectives of approaches. It furthermore reviews related literature surrounding building standards and urban city planning guidelines, focusing on the Australian Buildings Codes and Development Design Guidelines. The paper then presents a performance-based tall building design method that combines individual building and urban objectives for the control of winds impacting on tall buildings at the pedestrian, podium and upper levels. The performance-based framework therefore accounts for wind flow and load form design exploration in urban microclimates, which are defined by high density, multi-level building forms subject to acute variations in seasonal wind conditions.

\section{Defining Urban Resilience.}

Drawn from the literature of environmental and social sciences research, Leichenko (2011) investigates the notion of urban resilience from the perspective of the impacts of climate change. The study frames urban resilience in terms of the ability of a city or urban system to withstand a wide array of shocks and stresses. Leichenko's study highlights broad agreement among different fields of research regarding the need for cities to prepare for the effects of climate change and implement strategies for urban resilience so as to address a wider range of environmentally driven stresses and shocks. From this perspective, it is argued that efforts to promote urban development, sustainability, and resilience to climate change should be synthesized.

Similarly, Godschalk (2003) investigates resilient cities focusing on urban hazard mitigation focusing on natural disaster and terrorism. This view considers cities as a complex and interdependent systems that are vulnerable to threats from natural and terrorist hazards. Godschalk's approach proposes a strategy aimed at enabling cities to withstand both types of hazards, defining a 'resilient city' as a "sustainable network of physical systems", including buildings, infrastructure, and communities (encompassing both the formal and informal human associations that operate schools, agencies and organizations, etc.). From this standpoint hazard mitigation is defined as an action aimed at decreasing or eliminating long-term risk to people and property from the effects of environmental hazards. The scope of actions range from the development of structural engineering standards and building codes to land use, planning and property acquisition.

Based on a survey of related literature, a taxonomy of urban resilience is identified across the different environmental and social science domains. This taxonomy divides urban resilience into four categories, including:

(i) Urban ecological resilience - the ability of a city or urban system to absorb disturbance while retaining identity, structure and key processes (Alliance 2007),

(ii) Urban hazards and disaster risk reduction - the capacity of cities, infrastructure systems, and urban populations and communities to quickly and effectively recover from both natural and humanmade hazards such as hurricane and international terrorism (Coaffee 2008),

(iii) Resilience of urban and regional economies - focusing on the evolution of urban and regional economic and industrial systems (Pendall 2009), and

(iv) Promotion of resilience through urban governance and institutions - focusing on questions of how different types of institutional arrangements affect the resilience of local environments (Ostrom 2010).

Based on this brief review of the literature, the authors define urban resilience as a system that able to: (i) respond to uncertainty and change in climate conditions, (ii) respond to associated socialecological related risks, and (iii) reorganize and recover quickly from such changes, risks and disturbances. Consequently, this research investigates urban hazard mitigation from the perspective of tall building design, focusing on mitigating the impacts of strong and extreme winds at two inter-related 
scales: the building scale and urban city scale. The authors claim that in designing for these two scales simultaneously, urban resilience objectives can be better addressed.

\section{Tall Building Design And Controls For Wind}

High-density cities can be considered as a matrix of wind obstacles, comprising buildings of different sizes and forms, arranged at varying angles with different distances between them. Cities can suffer from poor ventilation and air quality problems, whilst others are subject to strong (sometimes extreme) wind conditions due to their geographical location or improper urban planning. Strong winds can have negative, long lasting effects on cities, their society, the environment, and economy; as is the case in cities such as New Orleans (Kurban \& Kato, 2009). As a result, building codes and city development design guidelines target improving the performance of wind loads on buildings and wind flow around buildings. To specify structural wind loads and acceptable wind flows precisely for every possible tall building shape in the context of its surrounding environment would result in provisions so complex as to be of limited use to designers. Therefore the specification of building codes and city development design guidelines involve some compromise.

\subsection{Building Scale Structural Wind Load Requirements}

One of the main objectives of the wind loading provisions defined in all building codes (e.g., Part 2 of Australia Standard AS 1170.1-1989), is to specify the minimum design loads on structures such as tall buildings. Tall building envelops are sensitive to a number of wind load factors, including the wind velocity approaching the site, the building height and geometry, and the influence of surrounding buildings on the local wind flow patterns. Building codes therefore usually specify loads along the wind direction for common shapes in open and suburban terrain. An exception is the building code AS/NZ 2002 , which provides provisions for the cross-wind direction as well. The cross-wind motion is mainly caused by fluctuations in the separating shear layers. Torsional motion can be caused due to imbalance in the instantaneous pressure distribution on each face of the building either due to oblique wind directions, unsteadiness in the approaching flow, partial sheltering and interference from surrounding buildings or due to the building's own shape and dynamic structural properties (Dagnew et al. 2009).

Further, studies show that in tall building designs, the crosswind and torsional response may exceed the along wind response in terms of both its limit state and serviceability requirements (Kareem 1985). Nevertheless, many standards, such as the AS/NZS 1170-2 provide procedures for evaluation of alongwind effects. For complex cases, these standards refer to physical model testing using a boundary layer wind tunnel, or BLWT, facility. The approach taken by some codes in predicting structural and wind loads on tall building envelops is to provide formulae that include a measure of conservatism, as might be expected based on the approach taken in deriving the formulae. Williams et al. (2003) assert that for small projects (e.g., $\leq 10$ stories) with simple geometries, code formulae are of sufficient accuracy for design purposes and conservative results may not have a major cost impact. However codes such as the AS/NZ 1170-2 recognize that for structures with more complex geometry detailed studies using wind tunnel tests are required since they yield more precise definitions of design loads, and more economical and risk consistent structural designs than code calculation methods.

\subsection{Urban Scale: City Development Design Guidelines}

In response to the mitigation of wind-related hazards, similar requirements are also typically requested by city-based (council) development design guidelines for assessing wind impacts of the design on pedestrians at street level. Concerns surround the effects of wind on pedestrians is primarily 
related to the reduction of wind velocity and its change rate. A wind impact statement is most often required by Australian city council authorities, which demonstrates via testing the impact that the design will have on the surrounding public realm. For tall building design proposals (typically $\geq 10$ stories), the results of a full wind tunnel test is typically required as part of the development application. Generally, submissions must identify and analyses the effects of wind conditions on pedestrians within the site, on the street at footpath and other surrounding areas. A comparative analysis of the current situation against the likely impacts created by the new development is also required; where impacts are shown to be detrimental to current conditions measures to reduce these impacts must be sought.

The City of Sydney Development Control Plan (DCP 2012) requires a wind effects report based on wind tunnel testing, which compares and analyses current versus proposed wind conditions, where high wind effects at the pedestrian level must be minimized. These provisions apply to buildings that are above 45m. Similarly, the R-Codes of Western Australia (WA 2015) require that high-rise buildings are set back from the site boundary so as to assist in reducing wind impacts. Perth's Planning Scheme (City of Perth 2013) requires a wind impact statement based on the results of full wind tunnel testing for new buildings that above 10m. Similarly, Melbourne's Planning Scheme (City of Melbourne 2016) requires analytical wind study for new buildings to provide a wind effects assessment that demonstrates that wind impacts will not adversely affect the amenity of the public realm and the scheme requires wind tunnel test as an assessment method. In addition, Melbourne's Planning Scheme provides proposed environmental wind criteria, including unacceptable and acceptable wind conditions based on wind velocity and the hourly average wind speed. This criteria assists designers to achieve good pedestrian activation along streets and in open space areas..

\section{Performance-Based Design Approach To Design Exploration}

The Building Codes and City Development Design Guidelines reviewed in the previous section vary relative to the scale that they are designed to address (structural building scale versus urban scale) and therefore their corresponding level of analysis. What they have in common concerns their typical testing requirements, which rely on wind tunnel testing or computational fluid dynamics (CFD) modelling. However compliance testing of tall building designs against these requirements are not performed until the later schematic and detailed design stages, when important design decisions about the building form and the relationship of the building envelop to its surrounding environment have already been made. Changes to the design of the tall building envelope are therefore costly as significant investment has been made to develop and detail the design across all disciplines involved (architecture, structure and all building services). Further, current building codes and design guidelines do not adequately address the interface between designing for the wind loads that act on a tall building's envelope and designing for wind flows that impact on pedestrians at street level

During the earlier stages of the design process, decision-making is aimed at searching through a range of potential design alternatives that 'satisfice' (Simon 1956) design requirements and constraints. Relative to climate-related hazards includes strong wind events, this requires finding alternative design solutions that satisfy the requirements of building codes and those of city development design guidelines. Most wind load requirements specified in building codes share common standards due to the nature of structural and physical properties. However, design guidelines vary from one region to another according to environmental conditions, including an area's vulnerability to wind-related hazards (tornados, typhoons, cyclones, etc.). When making design decisions about the envelope of a tall building in terms of its form, mass and height, the nature of surrounding wind conditions must first be identified. However, analyzing and evaluating design alternatives against specific wind load and wind flow performance criteria in order to meet competing design requirements in the early stages of the design process is a challenging task. It requires an understanding of the nature of aerodynamic 
behavior at both the building and urban scales that can only be synthesized using advance modelling and simulation methods (Khallaf \& Jupp 2016a).

The application of performance-based simulation and design exploration provides the necessary design decision support. The ultimate goal of computational simulation methods should not just be the analysis of prescribed shapes, but the automatic determination of the optimum shape for the intended application (Burkard 2000). The overall design exploration strategy developed here is based on the belief that problem formulation evolves during the process of searching and converging for the fittest (tall building envelop) solution; thus ultimately leading to a more informed and 'optimal' solution. In this way, design exploration is seen as being both a divergent and convergent process used to evolve and investigate a multidisciplinary design space that utilizes wind performance criteria with the intent of design discovery and to inform decision making trade-offs between the building and urban scales

Performance-based CFD simulation in wind engineering has seen increasing use in the assessment of risk associated with buildings subject to natural wind-related hazards (Huang et al. 2015, Khallaf \& Jupp 2016b). Accordingly, the remainder of this paper presents a framework for mitigating strong windrelated hazards based according to different wind load and wind flow criteria. The framework accounts for both building and urban parameters as well as topographical parameters derived from the urban geospatial environment.

The method employs computational fluid dynamics as its core simulation technique for the prediction of wind performance at different heights defined by the building's overall geometric form and its relationship with the surrounding building context. This technique includes the definition of grid discretization, domain sizes, and boundary conditions of the generated alternative solutions. The quality of the grid affects the accuracy of the flow solution (Blazek 2001). Two equations are based on the simulation techniques Euler equations for inviscid and the Navier-Stokes equations for viscous flow. Since a wide range of evolutionary algorithms have been proposed to address various design problems (including combinatorial and substitution algorithms), the design exploration process discovers design conditions and via gradual parametric experimentation characterizes what an optimal design looks like. Once this is known, the final solution can then be found through a convergent design optimization algorithm. The framework is detailed below and is based on five modules and seven steps carried out in a sequential manner as shown in Figure 1.

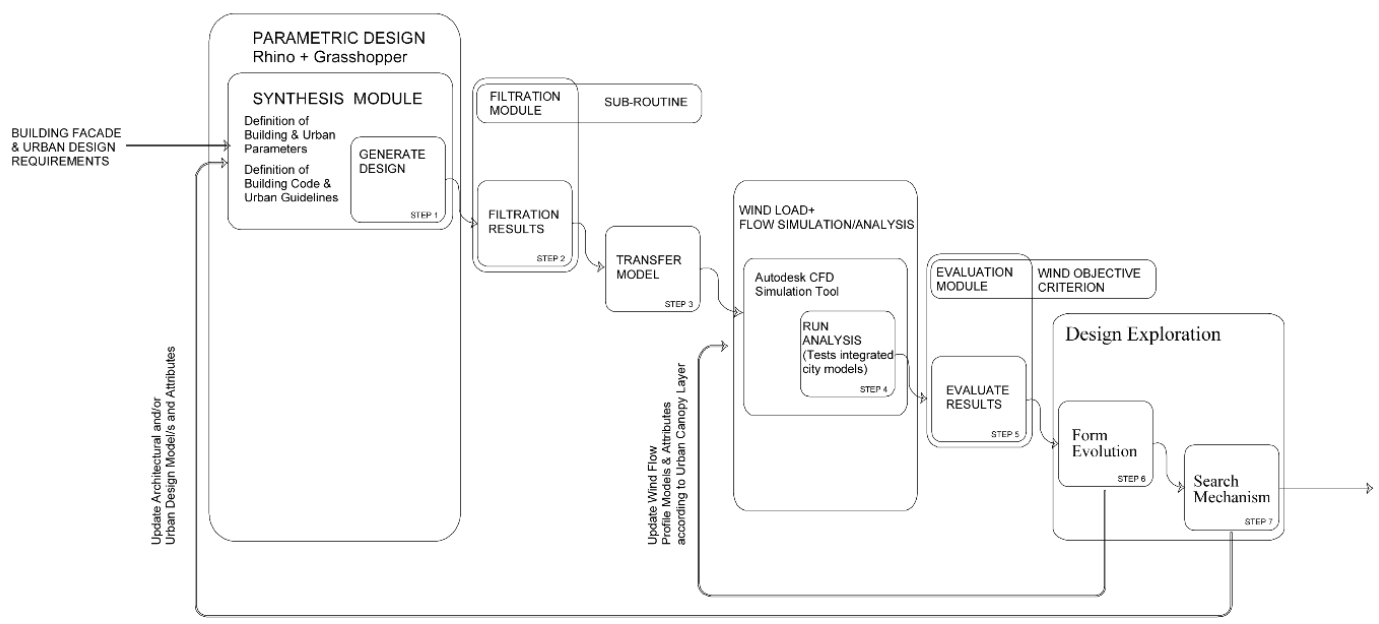

Figure 1 Performance-based Framework for Wind-Related Hazards in the Form Exploration of Tall Building Envelop Designs 
Design Generation: Consisting of objective functions, parameters and constraints. This module defines the objective functions and the boundary of design parameters and constraints. The system boundary is based on three sets of parameters and one set of constraints, namely: wind load and flow performance parameters, geometric parameters defining the criteria for the building envelope, urban parameters defining the criteria of the surrounding urban environment, and the topographical constraints defining slope categories). By assigning different values to the geometric and urban parameters, the values of the wind performance parameters are accordingly adjusted in parallel with the geometrical change of the tall building envelope. Consequently all possible design solutions can be generated. The flexible relations between geometries, wind load and flow performance can then be analysed by the subsequent module. The generative software Rhino/Grasshopper can be readily used as the parametric modelling tool and is suitable due to the flexibility of modelling rendering and design workflow. In addition, Genoform, a Grasshopper plug-in is adopted as a bi-directional approach to multi-objective problem solving. The model is a surface-based parametric rig composed of geometric primitives (points, polygons, and surface.

Filtration: Consisting of filtering functions that can evaluate the results of the Generation Module and compare results with regard to performance parameters derived from building codes and city development design guidelines. The objective of this module is to filter design solutions by discarding unmatched solutions that do not meet the appropriate wind load (building) and wind flow (urban) design criteria. Filtration Sub-Routine: An external constraints module extends the Filtration Module so as to consider other design constraints relevant to the tall building design brief, such as functional, layout, height and construction constraints, etc

Simulation \& Analysis: Consisting of the simulation of the flexible relationships between geometry and wind load and wind flow performance outcomes of the filtered design solutions (resulting from the previous module). The simulation workflow enables the analysis of the impact of the wind load on and wind flow around both the geometrical parameters and performance variables with the visualisation of data points assisting in the confirmation of different performance locations throughout the test site on all $\mathrm{X}, \mathrm{Y}$ and $\mathrm{Z}$ axes. Consequently, the change of performance parameters can be visualized within the system using this module. This assists the designer's understanding of the nature of wind load and flow at both building and urban scales. The Autodesk CFD Design Study Environment is used in this stage as this tool includes a range of simulation methods for analysing wind loads and flows. This stage therefore includes both building and urban CFD analysis. It enables the testing of model geometry relative to the building envelope in the context of the urban environment. Simulations are run for two general scenarios: (i) high winds in extreme weather conditions, and (ii) low winds in the case of stagnant air conditions

Evaluation: Consisting of comparative assessment. The Evaluation Module provides a quantitative assessment of the level of effectiveness of wind performance across design alternatives, comparing results from the previous module with wind performance objectives and criterion. This implies that there may be no single optimal solution but rather a whole set of possible solutions of equivalent or comparable quality (Abraham et al 2005). The main objective of this module is therefore to rank design solutions according to wind performance criteria at three levels and to assess performance across these levels, including the pedestrian (0-6m), podium (7-45m) and upper (above $46 \mathrm{~m})$ levels.

Design Exploration: Consisting of exploration processes which are aimed at evolving and searching for the most suitable design solution that satisfies the objective function (tested in the previous module) together with relevant compliance criteria (e.g., building code and design guidelines). This module includes a two-part exploration process, namely Form Evolution followed by Search Mechanism.

Form Evolution: develops the design solution via mutation of the fittest design solutions' parameters (building and urban) according to all 'performance levels', i.e., pedestrian (0-6m), podium $(7-45 \mathrm{~m}$ ) and upper (above $45 \mathrm{~m}$ ) levels. The purpose of mutation is to produce new design properties and features which will allow the system to improve the design solutions' geometric form and 
performance whilst limiting the number of the feasible alternative design solutions using a proven fitness function identified as a result of the Evaluation Module.

Search Mechanism: works as a space search mechanism. The designer in this stage searches for the optimum design solutions within the domain of feasible crossbred design solutions using the results of the wind performance objective criterion. The aim of this module is to identify the fittest design from among the available designs solutions based on both the design performance and the wind performance criteria. The objectives of design exploration may be variable and not constant depending on design and context requirements relative to wind velocity, directions, and turbulence. However, if the target design solution does not fit the performance criteria, the designer can implement changes in the initial design parameters defined in the Generation Module based on the current results, and perform another run of the module.

\section{Discussion}

The paper briefly reviewed literature surrounding designing for urban resilience and highlights the approaches relative to existing building standards and urban city planning guidelines. The paper then presented building codes and city development design guidelines pertaining to the design of tall building envelopes for wind loads and urban wind flow requirements focusing on the Australian cities. The paper highlighted the lack of performance-based form simulation and design exploration approaches to tall building and surrounding urban resilience, which can account for both scales relative to the control of the effects of high and low wind conditions. The authors, therefore, propose a generative parametric framework based on building and urban parameters and wind performance criteria that can manage dependencies between building and urban wind flows; thus supporting the exploration of tall building envelope designs. The benefits of using the framework surround the performance-based feedback which is valuable to decision-making in the early stages of design so as to mitigate wind-related hazards. Further work is aimed at verifying the framework in a case study of Melbourne.

\section{References}

Abraham, A., Jain, L. \& Goldberg, R. (Eds.) (2005). Evolutionary multi-objective optimization: Theoretical advances \& applications. New York: Springer Science

Alliance, R. (2007). Assessing resilience in social-ecological systems: a workbook for scientists. Resilience Alliance, Wolfville

AS/NZ1170.2 (2011). Australia/New Zealand Standard AS/NZS1170.2. (2011), Structural design actions. Part 2: Wind actions, jointly published by Standards Australia International Ltd \& Standards New Zealand

Khallaf, M. \& Jupp, J. (2016a). Designing for Urban Microclimates: Towards Multidisciplinary Optimisation of Wind Flow for Architectural and Urban Design, In eCAADE.

Khallaf, M. \& Jupp, J. (2016b). Performance-based Design of Tall Building Envelopes using Competing Wind Load and Wind Flow Criteria, In International High- Performance Built Environment Conference - A Sustainable Built Environment Conference 2016 Series (SBE16), iHBE 2016 Proceedings of SBE Conference, University of New South Wales.

Blazek, J. (2001). Computational Fluid Dynamics: Principles and Applications. Elsevier. New York, New York.

Burkard, R., Deuflhard, P., Jameson, A., Lions, J.L., \& Strang, G. (2000). Computational Mathematics Driven by Industrial Problems: Lectures Given at 1st Session of Centro Internazionale Matematico Estivo (CIME) Held in Martina Franca, Italy, June 21-27, 1999. Springer Science \& Business.

City of Melbourne (2016). Planning Scheme, City of Melbourne, Mel. 
City of Perth (2011). Planning Scheme No. 2, City of Perth, Perth.

City of Sydney (2012). Development Control Plan, Department of Planning and Environment, City of Sydney.

Coaffee, J. (2008). Risk, resilience, and environmentally sustainable cities. Energy Policy, 36(12), 4633-4638

Dagnew, A.K., Bitsuamalk, G.T., \& Ryan, M. (2009). Computational evaluation of wind pressures on tall buildings. The 11th American Conference on Wind Engineering. San Juan, Puerto Rico.

Godschalk, D.R. (2003). Urban hazard mitigation: creating resilient cities. Natural hazards review, 4(3), 136-143.

Huang, M.F., Li, Q., Chan, C.M., Lou, W.J., Kwok, K.C.S., \& Li, G. (2015). Performance-based design optimization of tall concrete framed structures subject to wind excitations. J. of Wind Eng. \& Ind. Aerodynamics, 139, 70-81.

Kareem, A., (1985), Lateral-Torsional Motion of Tall Buildings to Wind Loads, J. of Struct. Eng., SCE, 111 (11).

Kurban, H., \& Kato, M. (2009). Constructing Urban Vulnerability Index for Major US Cities.

Jupp JR. \& Awad R. (2017). BIM for FM and Information Requirements Management: Missing Lall, S. V., \& Deichmann, U. (2012). Density and disasters: economics of urban hazard risk. The World Bank Research Observer, 27(1), 74-105.

Leichenko, R. (2011). Climate change and urban resilience. Current opinion in environmental sustainability, 3(3), 164-168.

Meerow, S., Newell, J. P., \& Stults, M. (2016). Defining urban resilience: A review. Landscape and urban planning, 147, 38-49.

Ostrom, E. (2010). Polycentric systems for coping with collective action and global environmental change. Global Environmental Change, 20(4), 550-557

Pendall, R., Foster, K. A., \& Cowell, M. (2009). Resilience and regions: building understanding of the metaphor. Cambridge J. of Regions, Economy \& Society.

Simon, H.A. (1956). Rational choice and the structure of the environment. Psychological Review, $63,129-138$.

United Nations, (2009). Department of Economics \& United Nations. Dept. of Public Info., The millennium development goals report 2009. UN Publications.

WA R-Codes (2015) Western Australian Residential Design Codes (R-Codes), Western Australian Planning Commission

Williams, C. J., Conley, G., \& Kilpatrick, J. (2003). The Use of Wind Tunnels to Assist in Cladding Design for Buildings. In Performance of Exterior Building Walls. ASTM International. 